\title{
Self-Assembling Polycondensation of 4-Aminobenzaldehyde. Preparation of Star-Like Aggregates of Cone-Shaped Poly(azomethine) Crystals
}

\author{
Kunio KimUra,$^{\dagger}$ Jin-Huang ZhUang, Michiko KIDA, Yuhiko Yamashita, \\ and Yoshimitsu SAKAGUCHI* \\ Faculty of Environmental Science and Technology, Okayama University, 3-1-1 Tsushima-naka, \\ Okayama 700-8530, Japan \\ *Toyobo Research Center, Toyobo Co. Ltd., 1-1 Katata 2-Chome, Otsu 520-0292, Japan
}

(Received January 14, 2003; Accepted March 1, 2003)

\begin{abstract}
KEY WORDS Self-Assembling / Polycondensation / Poly(azomethine) / Crystallization /
Morphology /
\end{abstract}

Aromatic poly(azomethine)s belong to a class of high performance materials that are known because of their excellent thermal stability, good mechanical properties and environmental resistance, ${ }^{1-4}$ but more particularly as promising materials with optoelectrical, photonic and magnetic application..$^{5-8}$ Numerous types of aromatic poly(azomethine)s have been synthesized by the condensation between aromatic dialdehydes and diamines. However, their high melting points and low solubility usually make them inaccessible for processing by conventional techniques. In order to improve their intractability, several approaches such as the introduction into the main chain of flexible aliphatic segments, bulky lateral substituents or fluorine groups have been attempted so far. ${ }^{9-12}$

We have been studying on the morphology control of intractable polymers during solution polymerization, and succeeded in preparing the whiskers of $\operatorname{poly}(p-$ oxybenzoyl) and other aromatic polyesters by polymerization in liquid paraffin (LPF). ${ }^{13-18}$ These whiskers are formed by the reaction-induced crystallization of oligomers during solution polymerization. The polymer chains are aligned along the long axis of the whiskers and they show single crystal nature. This morphology and the chain alignment are desirable to endow the essential properties for industrial materials such as organic reinforcements. The formation mechanism of these whiskers contains the following three steps: (1) When the degree of polymerization of the oligomers exceed a critical value, they are precipitated from the solution to form lamellae. (2) The lamellae pile up in the form of needle-like crystals with spiral growth.
(3) Post-polymerization occurs topochemically in the needle-like crystals, and the whiskers consisting of high molecular weight extended polymer chains are eventually formed. ${ }^{14}$ The preparation method of the whisker can be recognized as the self-assembling polycondensation accompanied by the reaction-induced crystallization of oligomers, and it is a very valuable method for the morphology control of intractable polymers to overcome the antagonistic problem between intractability and properties.

In many reports it has been very difficult to obtain the high molecular weight poly(azomethine) (PAZM). One of reasons is that aromatic poly(azomethine)s are precipitated in the solution during polycondensation because of the low solubility. ${ }^{12}$ Much effort was devoted recently to preparing soluble and fusible aromatic poly(azomethine)s in many different ways. ${ }^{19-21}$ However, the modification of polymer chain structures sacrifices their essential properties derived from their straight rigid-rod structures. Precipitation during polymerization is of advantage to control the morphology by means of the reaction-induced crystallization of oligomers as described before. In this study, we report the morphology of PAZM crystals prepared by the selfassembling polycondensation of 4-aminobenzaldehyde (ABAH).

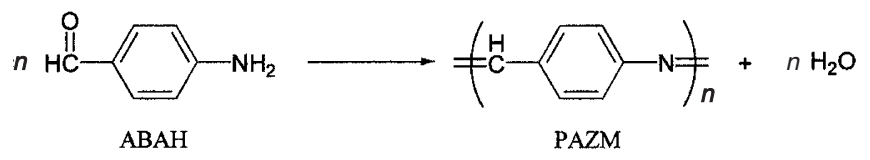

Scheme 1.

${ }^{\dagger}$ To whom correspondence should be addressed (Tel \& Fax: +81-86-251-8902, E-mail: polykim@cc.okayama-u.ac.jp). 


\section{EXPERIMENTAL}

\section{Materials}

ABAH was synthesized according to the previous study. ${ }^{22}$ LPF was purchased from Nacalai Tesque Co. Ltd and purified by vacuum distillation (220$240^{\circ} \mathrm{C} / 0.3 \mathrm{mmHg}$ ).

\section{Polymer Synthesis}

Into a cylindrical flask equipped with a mechanical stirrer and a gas inlet tube were placed $0.218 \mathrm{~g}$ of ABAH $(1.80 \mathrm{mmol})$ and $60 \mathrm{~mL}$ of LPF. The reaction mixture was heated up to $200^{\circ} \mathrm{C}$ under a slow stream of nitrogen with stirring. ABAH was completely dissolved at $160^{\circ} \mathrm{C}$ and then the stirring was stopped. Reaction temperature was maintained at $200^{\circ} \mathrm{C}$ for $5 \mathrm{~h}$. The precipitated crystals were collected by vacuum filtration at $200^{\circ} \mathrm{C}$, and washed with $n$-hexane and acetone.

\section{Characterization}

Morphology of the products was observed on SEM (Hitachi S-2150). The size of the crystal was determined by the average of over 80 observation values. Wide angle X-ray scattering (WAXS) was conducted on a diffractometer (Rigaku 4012K2) with nickelfiltered $\mathrm{CuK} \alpha$ radiation $(35 \mathrm{kV}, 20 \mathrm{~mA})$. FT-IR measurement was performed on IR spectrometer (JASCO FT-IR 350). Thermal properties were evaluated by DSC (PerkinElmer DSC-7) with a scanning rate of $10{ }^{\circ} \mathrm{C} \mathrm{min}^{-1}$ in nitrogen atmosphere. Thermal stability was measured on TGA (PerkinElmer TGA 7) at a heating rate of $20^{\circ} \mathrm{C} \mathrm{min}^{-1}$ in nitrogen atmosphere.

\section{RESULTS AND DISCUSSION}

Polymerizations were carried out in LPF at $200^{\circ} \mathrm{C}$ with varying the polymerization concentration of ABAH from 0.02 to $0.05 \mathrm{~mol} \mathrm{~L}^{-1}$. The polymerization results are summarized in Table I. ABAH was not dissolved into LPF at room temperature, but dissolved at $160^{\circ} \mathrm{C}$ on heating. When the polymerization was carried out at $0.02 \mathrm{~mol} \mathrm{~L}^{-1}$, the crystal was scarcely precipitated. In contrast to this, when the polymerization was carried out at higher concentration than $0.03 \mathrm{~mol} \mathrm{~L}^{-1}$, the solution became turbid after $5 \mathrm{~min}$ at $200^{\circ} \mathrm{C}$ due to the crystallization of oligomers and the dark yellow crystals were obtained after $5 \mathrm{~h}$ with the yield of $c a .30 \%$. The oligomers were not left in the solution after $5 \mathrm{~h}$. ABAH was vigorously sublimed at the beginning of the polymerization, and then the sublimation was stopped after $10 \mathrm{~min}$ because ABAH was changed into the oligomers by the reaction. Hence, the low yield of the crystals is due to the sublimation of ABAH. In generally, aromatic rigid-rod poly(azomethine)s are dissolved into only concentrated sulfuric acid. ${ }^{1,2}$ However, the obtained crystals were insoluble even in concentrated sulfuric acid, and therefore the chemical structure of the crystals could not be analyzed by NMR. This insolubility must be derived from the high crystallinity. FT-IR was measured to confirm the formation of PAZM. N-H of amino groups at 3420 $3250 \mathrm{~cm}^{-1}$ and $\mathrm{C}=\mathrm{O}$ of formyl groups at $1662 \mathrm{~cm}^{-1}$ in $\mathrm{ABAH}$ decreased significantly, and $\mathrm{N}=\mathrm{CH}$ of azomethine groups appeared newly at $1617 \mathrm{~cm}^{-1}$ in the spectrum of the crystals. This result confirms the formation of PAZM in the form of the crystals. Figure 1 shows the representative morphology of the crystals. The crystals prepared for $5 \mathrm{~h}$ are the star-like aggregates of the cone-shaped crystals, of which the average length is $0.5-0.6 \mu \mathrm{m}$ and tip angle is $c a .30^{\circ}$. The average length increases with the concentration. But it tends to be saturated at higher concentration, and the distribution of the length becomes broader with the concentration. Additionally, the crystals prepared at $0.05 \mathrm{~mol} \mathrm{~L}^{-1}$ are contaminated by the products exhibiting unclear morphology. The concentration of $0.05 \mathrm{~mol} \mathrm{~L}^{-1}$ is too high to obtain the crystals having clear habit. Figure 2 shows the WAXS profiles of the crystals prepared at $0.04 \mathrm{~mol} \mathrm{~L}^{-1}$ for different polymerization time. The broad and low-intense halo attributed to the amorphous region is hardly observed in the profile of the crystals prepared for $5 \mathrm{~h}$. The only one sharp Bragg-type reflection peak is observed at $2 \theta$ of $22.5^{\circ}$. This diffraction may correspond to the distance between the poly-

Table I. Results of polymerization ${ }^{\mathrm{a}}$

\begin{tabular}{|c|c|c|c|c|c|}
\hline \multirow{2}{*}{$\begin{array}{l}\text { Concentration } \\
\left(\mathrm{mol} \mathrm{L}^{-1}\right)\end{array}$} & \multirow{2}{*}{$\begin{array}{c}t_{\mathrm{t}}^{\mathrm{b}} \\
(\mathrm{min})\end{array}$} & \multirow{2}{*}{$\begin{array}{c}\text { Yield } \\
(\%)\end{array}$} & \multirow{2}{*}{ Morphology } & \multicolumn{2}{|c|}{ Size of Cone-shaped crystals } \\
\hline & & & & Length $(\mu \mathrm{m})$ & $\sigma^{\mathrm{c}}(\mu \mathrm{m})$ \\
\hline 0.02 & 5 & 2.0 & $-^{\mathrm{d}}$ & - & - \\
\hline 0.03 & 5 & 33.1 & cone-shaped & 0.45 & 0.07 \\
\hline 0.04 & 4 & 29.4 & cone-shaped & 0.59 & 0.07 \\
\hline 0.05 & 4 & 28.6 & cone-shaped, not clear & 0.63 & 0.12 \\
\hline
\end{tabular}

${ }^{\text {a}}$ Polymerizations were carried out at $200{ }^{\circ} \mathrm{C}$ for $5 \mathrm{~h}$. ${ }^{\mathrm{b}}$ Time when solution becomes turbid. ${ }^{\mathrm{c}}$ Standard deviation. ${ }^{\mathrm{d}}$ Not measured. 
mer chains, and it indicates that the crystalline structure may be described by a pseudohexagonal unit cell. The crystals possess extremely high crystallinity. Thermal stability of these crystals was measured on TGA in nitrogen atmosphere. $5 \mathrm{wt} \%$ loss temperatures of the crystals obtained at 0.03 and $0.04 \mathrm{~mol} \mathrm{~L}^{-1}$ are $494^{\circ} \mathrm{C}$ and $510^{\circ} \mathrm{C}$, respectively. These crystals did not show the melting behavior under decomposition temperature measured on DSC. PAZM crystals obtained here are in the highest class of thermally stable polymers.
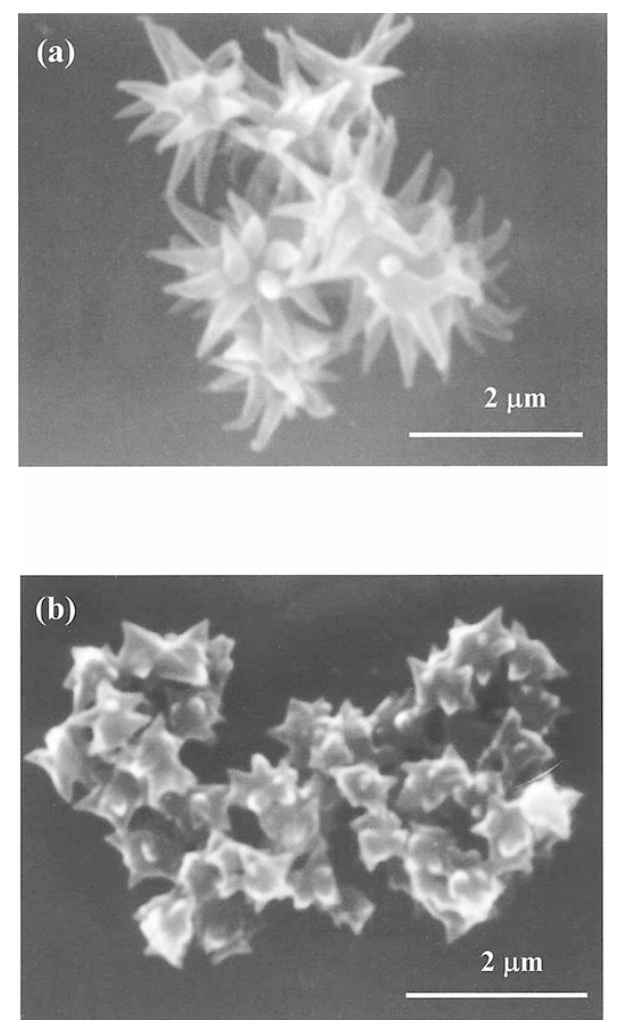

Figure 1. PAZM crystals prepared at $0.04 \mathrm{~mol} \mathrm{~L}^{-1}$ for (a) $5 \mathrm{~h}$ and (b) $15 \mathrm{~min}$.

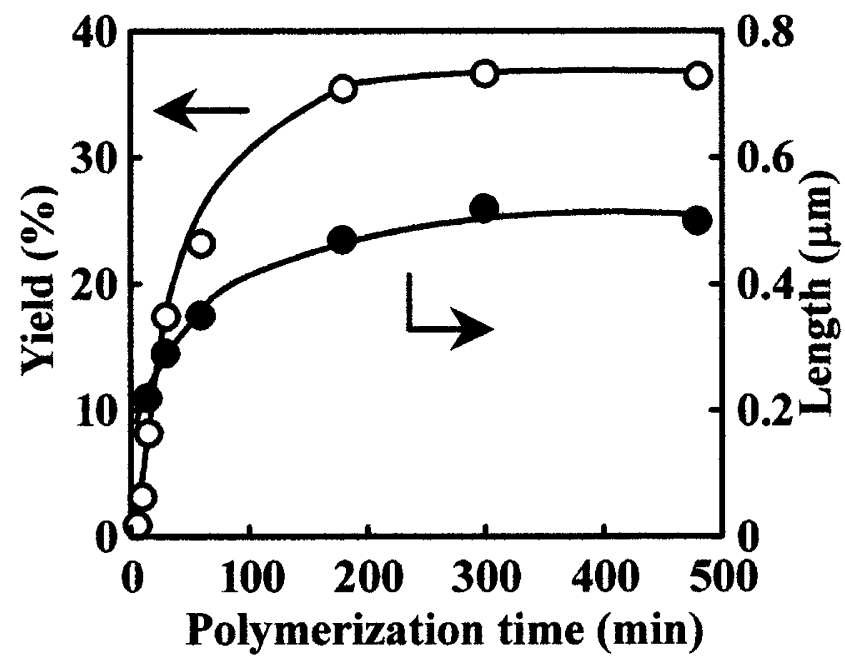

The changes in the yield, the morphology and the length of the crystals are examined during the polymerization to clarify the growth feature of the star-like aggregates of the cone-shaped crystals. Polymerization concentration was fixed at $0.04 \mathrm{~mol} \mathrm{~L}^{-1}$. The results are plotted in Figure 3. The length of the cone-shaped crystals increases with the yield, and they become constant after $3 \mathrm{~h}$. This good agreement between the length and the yield implies that the crystals are grown by the consecutive supply of the oligomers from the solution. The incipient precipitates obtained for 15 min exhibit many protuberances on their surfaces of which the length is $0.1-0.2 \mu \mathrm{m}$, as shown in Figure 1. The WAXS profiles of these crystals shown in Figure 2 reveal that the crystals prepared at the initial stage of polymerization

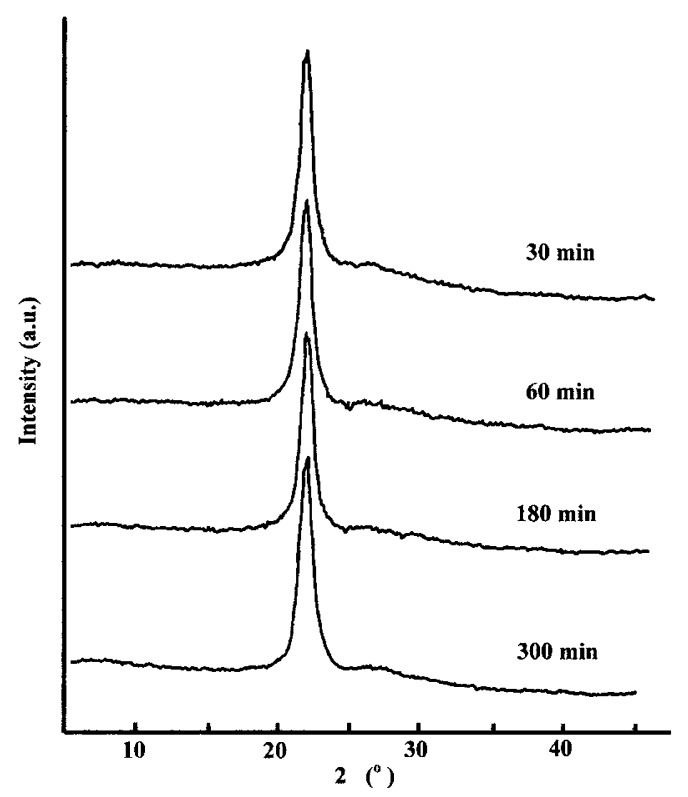

Figure 2. WAXS profile of the crystals prepared at $0.04 \mathrm{~mol} \mathrm{~L}^{-1}$ for $30 \mathrm{~min}, 60 \mathrm{~min}, 180 \mathrm{~min}$, and $300 \mathrm{~min}$.

Figure 3. Plots of (a) yield and length, and (b) absorbance ratio of $\mathrm{N}=\mathrm{CH}$ and $\mathrm{C}=\mathrm{O}$ of the crystals prepared at $0.04 \mathrm{~mol} \mathrm{~L}^{-1}$ as a function of polymerization time. 

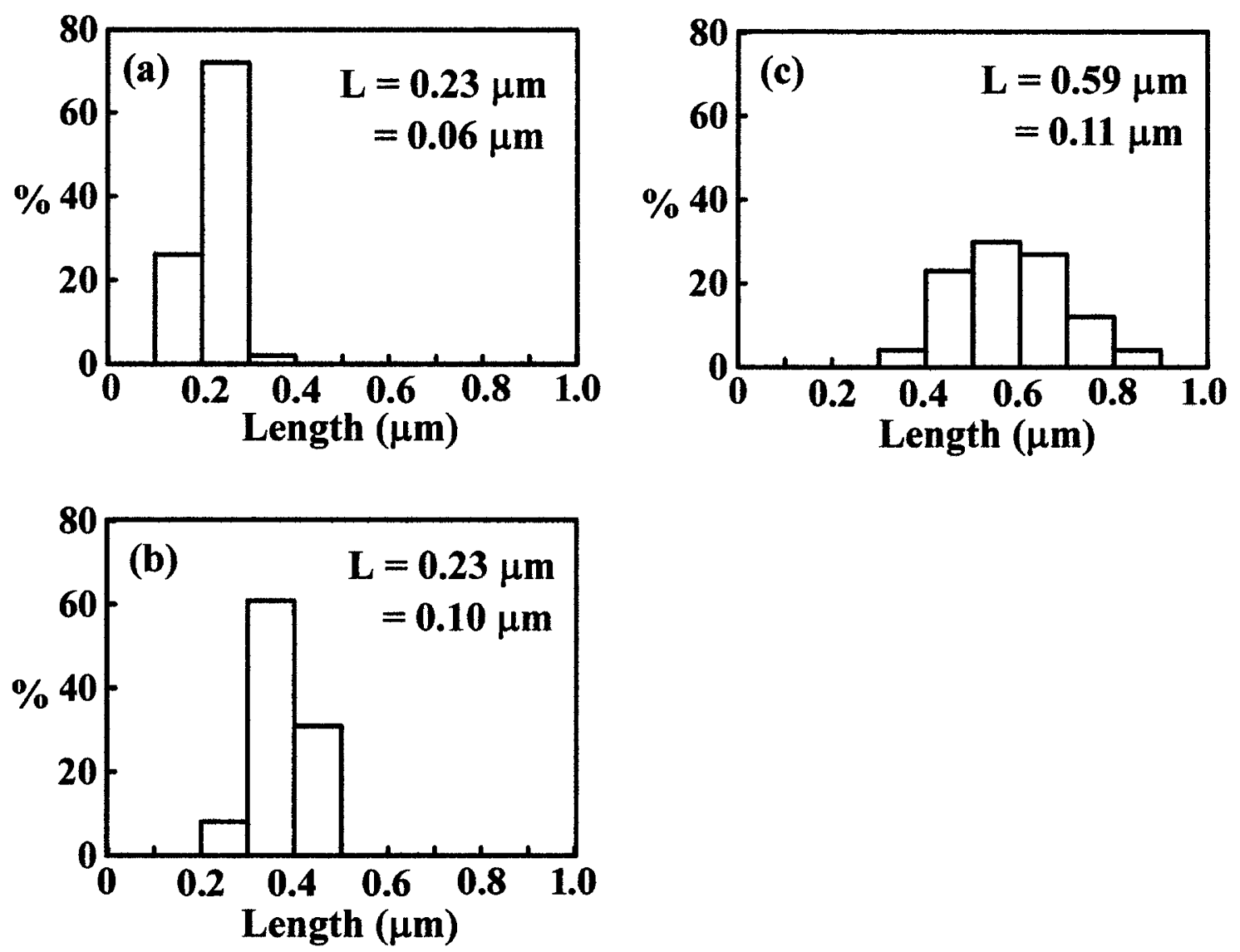

Figure 4. Distribution diagrams of length of cone-shaped crystals prepared at $0.04 \mathrm{~mol} \mathrm{~L}^{-1}$ for (a) $15 \mathrm{~min}$, (b) $60 \mathrm{~min}$, and (c) $300 \mathrm{~min}$.

possess crystallinity as high as that prepared for $5 \mathrm{~h}$. This indicates that they are grown by the crystallization of oligomers with maintaining high crystallinity. The growth feature of the cone-shaped crystals is different from that of the spherulites with fibrous substructures as observed for other polymers. ${ }^{23}$ Figure 4 illustrates the distribution diagrams of the length. The distribution becomes broader with time, but it keeps unimordality. This change in the distribution suggests that once the nucleation occurs, the oligomer precipitated after nucleation are only used to grow the crystals due to the advantage of surface energy for crystallization.

As described before, these crystals are insoluble into organic solvents, and therefore molecular weight cannot be directly determined by the conventional methods such as GPC, NMR, and viscosity measurement. FT-IR was measured to get the information about the change in molecular weight during polymerization. The absorbance ratio of $\mathrm{N}=\mathrm{CH}$ of azomethine group and $\mathrm{C}=\mathrm{O}$ of formyl group is plotted as a function of polymerization time, as shown in Figure 3. The ratio increases with time, and this indicates the increment of molecular weight during the crystal growth. Interestingly the ratio increases continuously after $3 \mathrm{~h}$ when the yield of the crystals is leveled off, and this reveals that the solidstate polymerization occurs between the oligomers in the crystals.

\section{REFERENCES}

1. P. W. Morgan, S. L. Kwolek, and T. C. Pletcher, Macromolecules, 20, 729 (1987).

2. P. W. Wojtkowski, Macromolecules, 20, 740 (1987).

3. H. H. Yang, "Aromatic High-Strength Fibers", Wiley-Interscience, New York, N.Y., 1989, p 641.

4. C. Yeakel, K. Gower, R. S. Mani, R. D. Allen, and D. K. Mohanty, Makromol. Chem., 194, 2779 (1993).

5. S. A. Jenekhe, C. J. Yang, H. Vanherzeele, and J. S. Meth, Chem. Mater, 3, 985 (1991).

6. C. J. Yang, S. A. Jenekhe, J. S. Meth, and H. Vanherzeele, Mater. Res. Soc. Symp. Proc., 247, 247 (1992).

7. C. J. Yang and S. A. Jenekhe, Chem. Mater., 6, 196 (1994)

8. C. J. Yang and S. A. Jenekhe, Macromolecules, 28, 1180 (1995).

9. D. Sek, Eur. Polym. J., 20, 923 (1984).

10. C. H. Li and T. C. Chang, Eur. Polym. J., 27, 35 (1991).

11. S. B. Park, H. Kim, W. C. Zin, and J. C. Jung, Macromolecules, 26, 1627 (1993).

12. T. Miyaji, C. Azuma, E. Asaoka, and S. Nakamura, J. Polym. Sci., Part A: Polym. Chem., 38, 1064 (2000).

13. Y. Yamashita and K. Kimura, in "Polymeric Materials Encyclopedia”, J. C. Salamone, Ed., CRC Press, Boca Raton, FL, 8707 (1996).

14. Y. Yamashita, Y. Kato, S. Endo, and K. Kimura, Makromol. Chem., Rapid Commun., 9, 687 (1989). 
15. K. Kimura, S. Endo, Y. Kato, and Y. Yamashita, Polymer, 35, 123 (1993).

16. K. Kimura and Y. Yamashita, Polymer, 35, 3311 (1994).

17. K. Kimura, S. Endo, Y. Kato, and Y. Yamashita, Polymer, 34, 1054 (1993).

18. K. Kimura, Y. Kato, T. Inaba, and Y. Yamashita, Macromolecules, 28, 255 (1995).

19. K. Park, T. Tani, M. Kakimoto, and Y. Imai, Macromol. Chem. Phys., 199, 1029 (1998).
20. P. W. Morgan, S. L. Kwole, and T. C. Pletcher, Macromolecules, 20, 729 (1987).

21. C. J. Yang and S. A. Jenekhe, Chem. Mater, 3, 878 (1991).

22. E. Campaigne, W. M. Budde, and G. F. Schaefer, Organic Synth., 31, 6 (1951).

23. B. Wunderlich, "Macromolecular Physics, Crystal Structure, Morphology, Defects", Academic Press, Inc., New York, N.Y., 1973, vol. 1, pp 339-341. 